\title{
Interruptions at Work from the Point of View of IT Professionals
}

\author{
Fruzsina Pataki-Bittó1* \\ ${ }^{1}$ Department of Ergonomics and Psychology, Faculty of Economic and Social Sciences, Budapest University of Technology and \\ Economics, H-1117 Budapest, Magyar Tudósok körútja 2., Hungary \\ *Corresponding author, e-mail: bittofruzsina@erg.bme.hu
}

Received: 20 December 2017, Accepted: 28 March 2018, Published online: 06 August 2018

\begin{abstract}
It is a major challenge nowadays to recruit and retain young professionals, especially IT professionals in Europe. Interior designers do their bests to create an office space that is more attractive for the young talents than the competitor's workspace. Modern workstyle is based on communication and collaboration and therefore modern office spaces are designed to support continuous communication and teamwork. In this research, we raise the question how IT professionals fit in this workstyle. The focus of this research is on how IT professionals feel about the different types of communication channels, which are those they identify as hindering factors, and how much their opinion differs from other professionals. During the research, we collected information from questionnaires asking about work environment, communication channels used in the workplace, individual communication preferences, and factors considered as disruptions. The questionnaire was completed by 191 Hungarian office workers from which 63 respondents were IT professionals. The most important result of the research shows that while IT professionals consider personal inquiries useful, many of them are dissatisfied with organized meetings. This research also outlines that IT professionals have an outstanding ability to block out office noise and to focus on work. With the conclusions we make suggestions to the organizations how to improve the communicational environment in order to support work efficiency.
\end{abstract}

\section{Keywords}

IT professionals, office environment, communication channels

\section{Introduction}

Collaboration became one of the key factors in business nowadays. (Kelly Services, 2016) The members of the $\mathrm{Y}$ and $\mathrm{Z}$ generations are more likely to prefer a company of collaborative culture with an impressive creative workspace than a company with rows of isolated cellular offices. However, collaboration does not exist without continuous communication, which leads to the problem, that collaborative work environment does not support work that demands concentration.

The frequent interruptions (personal inquiries, telephone calls, emails...) disturb the individual tasks and affect work efficiency (causing increased error rate and mental workload, time loss and emotional strain as well) (Baethge et al., 2014). Interruption researchers are analysing the effects, types and structure of interruptions and are working on solutions that reduce the negative effects.

In our survey conducted in 2016 we investigated the employees' overall impression of the disruptive factors and their opinion of the communication channels. We believe that their personal judgement is significant if the organization intends to improve not only the productivity but the level of job satisfaction as well (Pataki-Bitto and Németh, 2017). In the first phase of the research, the results of the survey were analysed regardless of the respondents' profession, but we did have a hypothesis that profession matters. Related literature often highlight the different communicational behaviour of IT professionals, therefore as a second phase of our research we analysed weather the opinion and the preference of the communication channels show differences between IT professionals and others.

\section{Related literature}

The following literature review covers two topics related to the research: the interruption types and effects in office environment, and the studies related to the personality of the IT professionals. 


\subsection{Interruption}

Thanks to the changing workstyle and the new communication technologies, the number of interruptions at office work environment reached a level that their negative effects can't be overlooked anymore. Interruption researchers are focusing on the effects of interruptions caused by communication channels and technologies, but noise pollution is also an important disruptive factor (Zaheeruddin and Garima, 2006), therefore the disruptions caused by the office environment (office noises, conversations nearby, colleagues' phone conversation, etc.) are often included in much research.

The effects of the interruptions are analysed by the source, importance, relevance, duration of the interruption and by the type and cognitivity of the interrupted (primary) task. Interruptions have two main categories: human and virtual interruptions, but the category of virtual interruption is often divided into subcategories by the communication channels: telephone, online call, instant messenger, updating software notifications, email notifications. (Sykes, 2011)

According to Baethge et al. the discovered negative effects of the interruptions are: increased mental workload, energetic cost (recovery effort), increased error rate connected to the feeling of failure, emotional strain and time loss (Baethge et al., 2014). Time loss means not only the duration of the interruption, but includes also the time that is needed to resume the original task after the disruption. A study focusing on the psychological effects highlights that interrupted people experience higher level of stress due to the higher level of workload and time pressure as mentioned before (Mark et al., 2008).

Based on the related studies there are two factors influencing most the negative effects of the interruptions which are the timing of the interruption and the cognitivity of the primary task. These factors are often connected. If a person is working on a high cognitive load task or he is at a stage of the task when the mental workload is high, the negative effect of an interruption is higher (Iqbal and Bailey, 2005). If the interruption occurs later in the primary task, especially when the user reaches a subtask boundary (when the mental workload is lower), the interruption causes fewer mistakes and the person can be more productive in the interrupting task as well (Nees and Fortna, 2015). An other study confirmed the importance of the timing: when the interruptions happen at subtask boundaries, the time required to complete the primary task and the error rate are significantly less than the other case when the interruptions are random (Bailey and Konstan, 2006).

Studies showed that if the interruption occurs at the right moment (low-workload moment) it reduces also the psychological cost of the interruptions: causing less annoyance, less frustration and lower level of time pressure (Adamczyk and Bailey, 2004).

Individual differences, personality measures were tested as well, whether they are influencing the level of negative effects of the interruptions, for example: polichronicity (Sanderson, 2012), working memory capacity (Drews and Musters, 2015), multitasking ability (Watson and Strayer, 2010), openness to experience and personal need for structure (Mark et al., 2008).

The relationship between a profession and the negative effects of interruption has not been investigated, only referred as the type of work matters due to the cognitivity.

\subsection{IT professionals' characteristics}

People often say that IT professionals are geeks. They are smart, but asocial, and even if they speak, they seems to use a different language, which makes it difficult to understand them. In the literature, there are studies concerning the characteristics and skills that an IT manager needs to have or needs to develop to be successful in business, and there are other studies investigating how personality matters in the software development processes. Yilmaz describes in his dissertation that the different software development methodologies and the different roles within the methodologies requires different set of skills (Yilmaz, 2013).

Willcoxson and Chatman collected a number of IT characteristics mentioned in the related literature, such as IT professionals prefer to work alone, they are inwardly focussed and better at interacting with computers than with others. Willcoxson and Chatman highlight in their study that in most cases researchers consider the lack of communication skills of the IT managers and the IT/business "culture gap" as a fact, but there is no real evidence that these exist (Willcoxson and Chatham, 2006).

In their research, Willcoxson and Chatman investigated the typical Jungian personality types of 489 IT managers by using the Myers-Briggs Type Indicator (MBTI). By using MBTI people are categorized into 16 different psychological types, which are the combinations of 4 basic attitude preferences (Introversion/Extraversion, Intuition/ Sensing, Feeling/Thinking, Perception/Judging). The results show that contrary to the expectations more than the half of the respondents were extroverts, while 
regarding the cognitive style, the NT (intuition-thinking) type got the highest rate (45\%) and ST (sensing-thinking) got $33.5 \%$. NT shows a theoritical approach with an appeal to imagination, while ST is a more practical and realistic style of thinking. Considering all personality traits the researchers found that ISTJ (13.5\%) and ESTJ $(12.7 \%)$ were the most frequent traits among their sample (Willcoxson and Chatham, 2006).

According to The Myers \& Briggs Foundation, the descriptions of these two personality traits are the following:

"ISTJ - Quiet, serious, earn success by thoroughness and dependability. Practical, matter-of-fact, realistic, and responsible. Decide logically what should be done and work toward it steadily, regardless of distractions. Take pleasure in making everything orderly and organized - their work, their home, their life. Value traditions and loyalty."

"ESTJ - Practical, realistic, matter-of-fact. Decisive, quickly move to implement decisions. Organize projects and people to get things done, focus on getting results in the most efficient way possible. Take care of routine details. Have a clear set of logical standards, systematically follow them and want others to also. Forceful in implementing their plans."

(Myers and Briggs Foundation, 2017)

Although ISTJ was the leading personality type in most research focusing on IT professionals' personality (Capretz, 2003), Yilmaz recognized a tendency that the recent studies report increased rate of extroversion compared to the previous ones. He explained this trend by the changing nature of the IT profession: traditionally an IT professional was software developer/programmer, while nowadays new roles that require more social interactions (such as interface designer, software tester and system analyst) are also emerged in IT profession (Yilmaz, 2013).

To find out more about social skills, Willcoxson and Chatham used another research method (FIRO-B) which led them to the conclusion that IT manangers have "a moderate level of social interaction and also social flexibility; i.e. such persons tend to be equally comfortable both alone and in large groups" (Willcoxson and Chatham, 2006).

Capretz colncluded that although his research shows that software engineers are varied by personality types they still seems to be a "unique group of individuals" thanks to the increased number of ISTJ type represented among them (Capretz, 2003).
In our study we investigate whether this unique group has a unique approach to communication channels and whether their experiences of disturbing factors in office environments differs from others.

\section{Interruption Survey}

The first phase of the survey was conducted in December 2016, the participants were recruited through email and social media. Our aim was to reach people who work in different environments, conditions and organizational culture. In one month, the survey was completed anonymously by 141 employees who do computer-based work in an office environment.

For the second phase of the research we set the goal to compare IT professionals with others. Among the 141 respondents $22.7 \%$ were IT professionals, but in the second phase for the comparison we intended to increase the size of the sample. After one week extension posted the questionnaire only for employees working in IT industry, the percentage of IT professionals reached $33 \%$ of the total number of 191 respondents.

$35.6 \%$ of the respondents are working in an open office environment, $35.1 \%$ in small offices (with 2-5 workstations in an office room), $18.8 \%$ in medium-size office rooms (with 6-20 workstations) and $11.5 \%$ in private offices. The majority of IT professionals are working in open office environment (46\%) and in small offices (33\%), while almost no one in private offices. The openspace office is a characteristic of multinational companies, whereas small offices are typical of Hungarian companies and institutions.

Some $30 \%$ of the people questioned are working in management positions. Among the IT professional respondents, the percentage of managers is less, $25 \%$.

The framework of the survey is based on the presented literature and includes the following topics:

1. Cognitivity of work

How many hours of work demands concentration on an average workday?

Do employees feel that they have trouble with completing tasks that demand concentration?

2. Communication channels

How do employees feel about personal communications? Do they prefer written or face-to-face communication at the workplace?

3. Interruption

Do employees feel that office noise is disruptive? 
In the employees' opinion, is there a communication type that keeps them from effective work?

\subsection{Cognitivity}

How many hours/day should employees spend on high cognitive load tasks?

As interruptions have the most destructive effect on high cognitive load tasks, it is important to know the proportion of cognitive load tasks during an average working day. Instead of the expression "high cognitive load task", we used the expression "task demanding concentration" for better understanding.

As Table 1 shows, in general $41 \%$ of the respondents indicated to have less than two hours of tasks demanding concentration per day, while $37 \%$ of respondents have 3-4 hours and $23 \%$ reported more than four hours of cognitive load task per day. Analyzing by professions, about the half of the respondents from other fields have less than 2 hours mental load tasks a day (which is consistent to the result of phase 1), while among IT professionals this rate is only $27 \%$. As Table 1 shows, the number of IT professionals who indicated more than 4 hours of tasks demanding concentration a day is significantly higher than the number of other respondents.

Is it possible to complete high cognitive load tasks at the workplace during working hours?

This research question aimed to determine whether those tasks demanding concentration were able to be completed during normal working hours or required extra working hours.

Generally speaking, $45 \%$ of the people questioned were not able to complete concentration demanding tasks during normal working hours. The result by professions shows that the percentage of IT professionals who can complete their tasks during normal working hours is significantly higher (70\%) than at the others (48\%). (Table 2)

How many hours of mental load task can be completed during an average working day?

Table 1 Hours of concentration

\begin{tabular}{|c|c|c|c|c|c|c|}
\hline & & \multicolumn{5}{|c|}{ Hours of concentration per day } \\
\hline & & less than 1 & $1-2$ & $3-4$ & more than 4 & Total \\
\hline \multirow{3}{*}{$\begin{array}{l}\text { IT } \\
\text { professionals }\end{array}$} & Count & 0 & 17 & 23 & 23 & 63 \\
\hline & $\%$ within profession & $0.0 \%$ & $50.8 \%$ & $56.6 \%$ & $40.0 \%$ & $100.0 \%$ \\
\hline & Adjusted Residual & -2.0 & -1.9 & 0.0 & 3.2 & \\
\hline \multirow{3}{*}{$\begin{array}{l}\text { Other } \\
\text { professionals }\end{array}$} & Count & 8 & 53 & 47 & 20 & 128 \\
\hline & $\%$ within profession & $100.0 \%$ & $49.2 \%$ & $43.4 \%$ & $60.0 \%$ & $100.0 \%$ \\
\hline & Adjusted Residual & 2.0 & 1.9 & 0.0 & -3.2 & \\
\hline \multirow[b]{2}{*}{ Total } & Count & 8 & 70 & 70 & 43 & 191 \\
\hline & $\begin{array}{l}\% \text { within Hours of } \\
\text { concentration }\end{array}$ & $4.2 \%$ & $36.6 \%$ & $36.6 \%$ & $22.5 \%$ & $100.0 \%$ \\
\hline
\end{tabular}

Pearson Chi-Square $=14.512, \mathrm{p}<0.01$

Table 2 Completion of work

\begin{tabular}{|c|c|c|c|c|}
\hline & & $\begin{array}{l}\text { In order to complete } \\
\text { concentration demanding tasks } \\
\text { I go earlier to work or stay late. }\end{array}$ & $\begin{array}{l}\text { I'm able to complete } \\
\text { concentration demanding tasks } \\
\text { during normal working hours. }\end{array}$ & Total \\
\hline \multirow{3}{*}{$\begin{array}{l}\text { IT } \\
\text { professionals }\end{array}$} & Count & 19 & 44 & 63 \\
\hline & $\%$ within profession & $30.2 \%$ & $69.8 \%$ & $100.0 \%$ \\
\hline & Adjusted Residual & -2.8 & 2.8 & \\
\hline \multirow{3}{*}{$\begin{array}{l}\text { Other } \\
\text { professionals }\end{array}$} & Count & 66 & 62 & 128 \\
\hline & $\%$ within profession & $100.0 \%$ & $60.0 \%$ & $100.0 \%$ \\
\hline & Adjusted Residual & 2.8 & -2.8 & \\
\hline \multirow{2}{*}{ Total } & Count & 85 & 106 & 191 \\
\hline & $\%$ within profession & $44.5 \%$ & $55.5 \%$ & $100.0 \%$ \\
\hline
\end{tabular}

Pearson Chi-Square $=7.831, \mathrm{p}<0.01$ 
At this question we analyse separately the IT professionals and the other respondents. For IT professionals the hours of the concentration demand task does not make a significant difference, the rate of those who can complete their tasks during a normal working day is between $65 \%$ and $78 \%$ for the three categories (Table 3). By analysing the respondents from other fields, the results show that less than one hour per day of cognitive load tasks can be performed during normal working hours, while about half of those workers who have more than that have to go in earlier or stay late to complete their tasks (Pearson ChiSquare $=10.83, \mathrm{p}<0.01$ ) (Table 3).

We did have an assumption that those who are working in open plan office find it harder to complete concentration-demanding tasks during normal working hours, but the result of this survey suggests that the size of the office does not make significant differences. Although the result is not significant it is worth to mention that the medium size office room showed the highest rate $(69 \%)$ for completing concentration demand tasks, at the other office types this rate was $50-55 \%$.

\subsection{Communication channels}

\section{How do employees feel about personal inquiries?}

To express the approach to personal inquiries, respondents had to choose between statements. The pair of statements referred to the usefulness of the personal inquiries: $80.6 \%$ of respondents think that face-to-face conversations are useful, whereas $19.4 \%$ agree with the statement that face-to-face conversations take up too much valuable working time. (Table 4) This fact implies that the majority of employees consider personal inquiries useful. The approach to personal inquiries does not significantly differ by professions, although the percentage of IT professionals who find personal inquiries useful is even higher than among others.

Which type do employees prefer at the workplace?

Some $67 \%$ of those questioned prefer personal (face-toface) incoming inquiries at the workplace, whereas 33\% prefer when the questions are in written forms of communication. As Table 5 shows, IT professionals prefer personal communication as much as the respondents with different professions.

By checking the opposite direction of communication: it turns out that when the employee has to ask a question the most commonly used communication type is personal inquiry as well (Table 6). IT professionals use instant messenger more often and use phones less often than others. To the question what makes the difference between those who prefer written and those who prefer face-to-face communication, we did not find any answer within this survey (position, type of workplace, size of office room, work

Table 3 Completion of work by hours of concentration

\begin{tabular}{|c|c|c|c|c|c|c|}
\hline & & & \multicolumn{2}{|c|}{$\begin{array}{c}\text { In order to complete concentration } \\
\text { demanding tasks I go earlier to work or } \\
\text { stay late. }\end{array}$} & \multicolumn{2}{|c|}{$\begin{array}{l}\text { I'm able to complete concentration } \\
\text { demanding tasks during normal } \\
\text { working hours. }\end{array}$} \\
\hline & & & Others & IT & Others & IT \\
\hline \multirow{14}{*}{$\begin{array}{l}\text { Hours of } \\
\text { concentration } \\
\text { per day }\end{array}$} & \multirow{3}{*}{ less than 1} & Count & 0 & 0 & 8 & 0 \\
\hline & & $\%$ within hours & $0.0 \%$ & $0.0 \%$ & $100.0 \%$ & $0.0 \%$ \\
\hline & & $\begin{array}{l}\text { Adjusted } \\
\text { Residual }\end{array}$ & -3.0 & & 3.0 & \\
\hline & \multirow{3}{*}{$1-2$} & Count & 28 & 6 & 25 & 11 \\
\hline & & $\%$ within hours & $52.8 \%$ & $35.3 \%$ & $47.2 \%$ & $64.7 \%$ \\
\hline & & $\begin{array}{l}\text { Adjusted } \\
\text { Residual }\end{array}$ & 0.2 & 0.5 & -0.2 & -0.5 \\
\hline & \multirow{3}{*}{$3-4$} & Count & 29 & 5 & 18 & 18 \\
\hline & & $\%$ within hours & $61.7 \%$ & $21.7 \%$ & $38.3 \%$ & $78.3 \%$ \\
\hline & & $\begin{array}{l}\text { Adjusted } \\
\text { Residual }\end{array}$ & 1.7 & -1.1 & -1.7 & 1.1 \\
\hline & \multirow{3}{*}{ more than 4} & Count & 9 & 8 & 11 & 15 \\
\hline & & \% within hours & $45.0 \%$ & $34.8 \%$ & $55.0 \%$ & $65.2 \%$ \\
\hline & & $\begin{array}{l}\text { Adjusted } \\
\text { Residual }\end{array}$ & -0.6 & 0.6 & 0.6 & -0.6 \\
\hline & \multirow{2}{*}{ Total } & Count & 66 & 19 & 62 & 44 \\
\hline & & \% within hours & $51.6 \%$ & $30.2 \%$ & $48.4 \%$ & $69.8 \%$ \\
\hline
\end{tabular}


Table 4 Approach to face-to-face communication

\begin{tabular}{llccc}
\hline & & $\begin{array}{c}\text { I think that the face-to-face } \\
\text { conversations, chats are usually } \\
\text { useful }\end{array}$ & $\begin{array}{c}\text { The face-to-face conversations, } \\
\text { chats take away too much } \\
\text { useful time. }\end{array}$ & Total \\
\hline \multirow{2}{*}{$\begin{array}{l}\text { IT } \\
\text { professionals }\end{array}$} & Count & 53 & 10 & 63 \\
& Adjusted Residual & $84.1 \%$ & $15.9 \%$ & $100.0 \%$ \\
\hline \multirow{2}{*}{$\begin{array}{l}\text { Other } \\
\text { professionals profession }\end{array}$} & Count & 0.9 & -0.9 & 128 \\
& \% within profession & 101 & 27 & $100.0 \%$ \\
\hline \multirow{2}{*}{ Total } & Adjusted Residual & $78.9 \%$ & $21.1 \%$ & 191 \\
& Count & -0.9 & 0.9 & $100.0 \%$ \\
\hline
\end{tabular}

Table 5 Preferred incoming communication form at work

\begin{tabular}{llccc}
\hline \multicolumn{4}{c}{ Preferred communication form at work } \\
& & written & face-to-face & Total \\
\hline \multirow{2}{*}{ IT professionals } & Count & 20 & 43 & 63 \\
& \% within profession & $31.7 \%$ & $68.3 \%$ & $100.0 \%$ \\
& Adjusted Residual & -0.3 & 0.3 & 128 \\
Other professionals & \% within profession & $33.6 \%$ & 65 & $100.0 \%$ \\
& Adjusted Residual & 0.3 & -0.3 & 191 \\
\hline \multirow{2}{*}{ Total } & Count & 63 & 128 & $100.0 \%$ \\
\hline
\end{tabular}

Table 6 Preferred communication channel

\begin{tabular}{|c|c|c|c|c|c|c|}
\hline & & \multicolumn{5}{|c|}{ If I have a question to a colleague (working in the same building) I ask him/her... } \\
\hline & & $\begin{array}{l}\text { on instant } \\
\text { messenger }\end{array}$ & on email & personally & $\begin{array}{l}\text { on phone/ } \\
\text { online call }\end{array}$ & Total \\
\hline \multirow{3}{*}{ IT professionals } & Count & 13 & 10 & 29 & 11 & 63 \\
\hline & $\%$ within profession & $20.6 \%$ & $15.9 \%$ & $46.0 \%$ & $17.5 \%$ & $100.0 \%$ \\
\hline & Adjusted Residual & 1.8 & 0.5 & -0.6 & -1.2 & \\
\hline \multirow{3}{*}{ Other professionals } & Count & 14 & 17 & 65 & 32 & 128 \\
\hline & $\%$ within profession & $1.9 \%$ & $13.3 \%$ & $50.8 \%$ & $25.0 \%$ & $100.0 \%$ \\
\hline & Adjusted Residual & -1.8 & -0.5 & 0.6 & 1.2 & \\
\hline \multirow[b]{2}{*}{ Total } & Count & 27 & 27 & 94 & 43 & 191 \\
\hline & $\begin{array}{l}\% \text { within Hours of } \\
\text { concentration }\end{array}$ & $14.1 \%$ & $14.1 \%$ & $49.2 \%$ & $22.5 \%$ & $100.0 \%$ \\
\hline
\end{tabular}


schedule, age or sex do not make a difference). We believe that personality does play a role.

\subsection{Interruption}

In the employees' opinion, is there a communication type that keeps them from effective work?

Here, the intention was to find out if employees feel any of the communication types as a delay or setback factor at work (Table 7).

Almost a quarter of the people questioned do not feel that any of the communication types (listed) is influencing their performance badly, while about three quarters feel that one of the communication types has a negative effect on their work. Personal inquiries and email got the highest rate with $20 \%$ and $18 \%$, respectively, followed by the telephone and the planned meeting (12\%).

The answers of IT professionals differ significantly from others. The largest number (22\%) of IT professionals were on the opinion that planned meetings set them back from efficient work, while among others only $6 \%$ felt the same and email got the highest rate with $22 \%$. Interestingly only $10 \%$ of IT professionals indicated email as the most frequent setback factor.

\section{Do employees feel that office noise is disruptive?}

In general, the result shows that the efficiency of over one third of people is influenced by environmental noise. Some $27 \%$ of the IT professionals and $45 \%$ of the respondents from other fields chose the following statement: "The noises of the office environment (for example door opening/closing, steps or phone calls of colleagues) is very disturbing during work that requires concentration." This fact indicates that IT professionals have an improved ability to focus on a task, they are significantly better in blocking out the environmental noises compared to the others.

\section{Conclusions}

This section provides a review of the main findings of the survey. In conclusion, the results clearly show that it is worth to investigate separately the needs and preferences of IT professionals as they differ from others in some respects.

In general the proportion of cognitive load tasks a day is higher for an IT professional than the average. Even so most IT professionals succeed to complete concentration demand tasks during normal working hours. The survey indicates explanation of their better performance (regarding the completion of concentration demand tasks) but it also might be related to other circumstances, such as the increasing demand of IT professionals - which makes them highly valued, and managers might pay more attention on their moderate workload and set achievable goals.

The size of the offices and the type of separation is always a question in an office environment to find the right solution that supports collaboration but leaves space for the individual work as well. The result of the survey shows that although office noise is considered as a common problem for the employees who need to focus on work, IT professionals are more capable of blocking out the environmental noise than others. This result corresponds with the related literature, which names two leading personality traits: ISTJ and ESTJ. The description of ISTJ by the Myers and Briggs Foundation includes an approach to distractions: „decide logically what should be done and work toward it steadily, regardless of distractions", and ESTJ is also describes a person who "focus on getting results in the most efficient way possible" (Myers and Briggs Foundation, 2017). Although it seems that IT professionals are outstanding in focusing on their tasks, according to the result of our survey, the work efficiency of more than the quarter of IT professionals are still influenced by the noise pollution.

Regarding communication types one of the main goals of the research was to find out which communication channels are considered effective and which are considered as setback factors.

Much research examine the negative effects of the increasing email communication and it is also found that the feeling of email overload contributes to low work engagement (Reinke and Chamorro-Premuzic, 2014). Our survey result shows that for the other than IT professional respondents email is indeed the communication channel that disturbs the most, but not for IT professionals. IT professionals seems to handle emails better than others. This result can be explained by the better knowledge of email software settings, but the reason can also be the ability to neglect distractions and the ability to focus on work.

IT professionals feel that planned meetings keep them back the most from work. Although there's no doubt that the planned meetings are important parts of the software development processes, based on this survey managers should take it into consideration how to reduce the number and improve the efficiency of these meetings.

The results of the survey regarding the communicational habits and preferences of the IT employees does not support the existing stereotypes. IT professionals considered asocial, while the result of this survey shows that they do prefer personal communication over virtual. The approach to personal inquiries is two-sided though: on the 
Table 7 Communication forms as setback factor

\begin{tabular}{|c|c|c|c|c|c|}
\hline & & & IT professionals & Other professionals & Total \\
\hline & & Count & 3 & 5 & 8 \\
\hline & Instant messenger & $\%$ within profession & $4.8 \%$ & $3.9 \%$ & $4.2 \%$ \\
\hline & & Adjusted Residual & 0.3 & -0.3 & \\
\hline & & Count & 6 & 28 & 34 \\
\hline & Email & $\%$ within profession & $9.5 \%$ & $21.9 \%$ & $17.8 \%$ \\
\hline & & Adjusted Residual & -2.1 & 2.1 & \\
\hline & & Count & 5 & 8 & 13 \\
\hline & $\begin{array}{l}\text { Informal } \\
\text { communication } \\
\text { (non-work related) }\end{array}$ & $\%$ within profession & $7.9 \%$ & $6.3 \%$ & $6.8 \%$ \\
\hline & & Adjusted Residual & 0.4 & -0.4 & \\
\hline & & Count & 14 & 8 & 22 \\
\hline & Meeting (planned) & $\%$ within profession & $22.2 \%$ & $6.3 \%$ & $11.5 \%$ \\
\hline & & Adjusted Residual & 3.3 & -3.3 & \\
\hline \multirow{14}{*}{$\begin{array}{l}\text { I often feel that because of too } \\
\text { much/many... I can't get on } \\
\text { with my tasks }\end{array}$} & & Count & 12 & 27 & 39 \\
\hline & $\begin{array}{l}\text { Personal inquiries } \\
\text { (work related) }\end{array}$ & $\%$ within profession & $19.0 \%$ & $21.1 \%$ & $20.4 \%$ \\
\hline & & Adjusted Residual & -0.3 & 0.3 & \\
\hline & & Count & 5 & 18 & 23 \\
\hline & Telephone & $\%$ within profession & $7.9 \%$ & $14.1 \%$ & $12.0 \%$ \\
\hline & & Adjusted Residual & -1.2 & 1.2 & \\
\hline & & Count & 2 & 5 & 7 \\
\hline & Other & $\%$ within profession & $3.2 \%$ & $3.9 \%$ & $3.7 \%$ \\
\hline & & Adjusted Residual & -0.3 & 0.3 & \\
\hline & & Count & 16 & 29 & 45 \\
\hline & I don't feel that & $\%$ within profession & $25.4 \%$ & $22.7 \%$ & $23.6 \%$ \\
\hline & & Adjusted Residual & 0.4 & -0.4 & \\
\hline & & Count & 63 & 128 & 191 \\
\hline & Total & $\%$ within profession & $100.0 \%$ & $100.0 \%$ & $100.0 \%$ \\
\hline
\end{tabular}

Pearson Chi-Square $=14.818, \mathrm{p}<0.01$

one hand employees mostly agree that personal inquiries are useful and consider it as the most efficient way of communication, on the other hand personal inquiries turned out to be one of the most common setback factor at work (regardless of profession).
We believe that organizations should educate employees how to use the communication channels effectively and raise the awareness of the negative effects of unnecessary interruptions to improve the overall performance and the satisfaction of employees. 


\section{References}

Adamczyk, P. D., Bailey, B. P. (2004) "If not now when?: the effects of interruption at different moments within task execution", In: Proceedings of the SIGCHI Conference on Human Factors in Computing Systems, Vienna, Austria, pp. 271-278. https://doi.org/10.1145/985692.985727

Baethge, A., Rigotti, T., Roe, R. A. (2015) "Just more of the same, or different? An integrative theoretical framework for the study of cumulative interruptions at work", European Journal of Work and Organizational Psychology, 24(2), pp. 308-323. https://doi.org/10.1080/1359432X.2014.897943

Bailey, B. P., Konstan, J. A. (2006) "On the need for attention-aware systems: Measuring effects of interruption on task performance, error rate, and affective state", Computers in Human Behavior, 22(4), pp. $685-708$. https://doi.org/10.1016/j.chb.2005.12.009

Capretz, L. F. (2003) "Personality Types in Software Engineering", International Journal of Human-Computer Studies, 58(2), pp. 207-214. https://doi.org/10.1016/S1071-5819(02)00137-4

Drews, F. A., Musters, A. (2015) "Individual differences in interrupted task performance: One size does not fit all", International Journal of Human-Computer Studies, 79, pp. 97-105. https://doi.org/10.1016/j.ijhcs.2015.01.003

Iqbal, S., Bailey, B. (2005) "Investigating the effectiveness of mental workload as a predictor of opportune moments for interruption", In: CHI '05 Extended Abstracts on Human Factors in Computing Systems, Portland, OR, USA, pp. 1489-1492. https://doi.org/10.1145/1056808.1056948

Kelly Services, Inc. (2016) "The collaborative work environment", Kelly Services, Inc. 16-0019, [online] Available at: https:/www.kellyservices.com/global/siteassets/3-kelly-global-services/uploadedfiles/16-0019_2015_kgwi_topic5_ebook.pdf [Accessed: 21 April 2017]

Mark, G., Gudith, D., Klocke, U. (2008) "The cost of interrupted work: more speed and stress" In: Proceedings of the SIGCHI Conference on Human Factors in Computing Systems, Florence, Italy, pp. $107-110$. https://doi.org/10.1145/1357054.1357072

Myers \& Briggs Foundation (2017) "The 16 MBTI Types", [online] Available at: http://www.myersbriggs.org/my-mbti-personality-type/mbti-basics/the-16-mbti-types.htm [Accessed: 12 November 2017]
Nees, M. A., Fortna, A. (2015) "A comparison of human versus virtual interruptions, Ergonomics, 58(5), pp. 852-856. https://doi.org/10.1080/00140139.2014.990934

Pataki-Bittó, F., Németh, E. (2017) "Interruption overload in an office environment", International Journal of Economics and Management Engineering, 11(7), pp. 1763-1770. [online] Available at: urn:dai:10.1999/1307-6892/10007464 [Accessed: 20 Sptember 2017]

Reinke, K., Chamorro-Premuzic, T. (2014) "When email use gets out of control: Understanding the relationship between personality and email overload and their impact on burnout and work engagement", Computers in Human Behavior, 36, pp. 502-509. https://doi.org/10.1016/j.chb.2014.03.075

Sanderson, K. R. (2012). "Time Orientation in Organizations: Polychronicity and Multitasking", PhD Dissertation, Florida International University. https://doi.org/10.25148/etd.FI12112701

Sykes, E. R. (2011). "Interruptions in the workplace: A case study to reduce their effects", International Journal of Information Management, 31(4), pp. 385-394. https://doi.org/10.1016/j.ijinfomgt.2010.10.010

Watson, J. M., Strayer, D. L. (2010) "Supertaskers : Profiles in extraordinary multitasking ability", Psychonomic Bulletin \& Review, 17(4), pp. $479-485$. https://doi.org/10.3758/PBR.17.4.479

Willcoxson, L., Chatham, R. (2006) "Testing the accuracy of the IT stereotype: Profiling IT managers' personality and behavioural characteristics", Information \& Management 43(6), pp. 697-705. https://doi.org/10.1016/j.im.2004.04.009

Yilmaz, M. (2013) "A Software Process Engineering Approach to Understanding Software Productivity and Team Personality Characteristics", PhD Dissertation, Dublin City University, Available at: http://doras.dcu.ie/17731/1/Murat_thesis.pdf [Accessed: 9 November 2017]

Zaheeruddin, Garima (2006) "A neuro-fuzzy approach for prediction of human work efficiency in noisy environment", Applied Soft Computing, 6(3), pp. 283-294. https://doi.org/10.1016/j.asoc.2005.02.001 